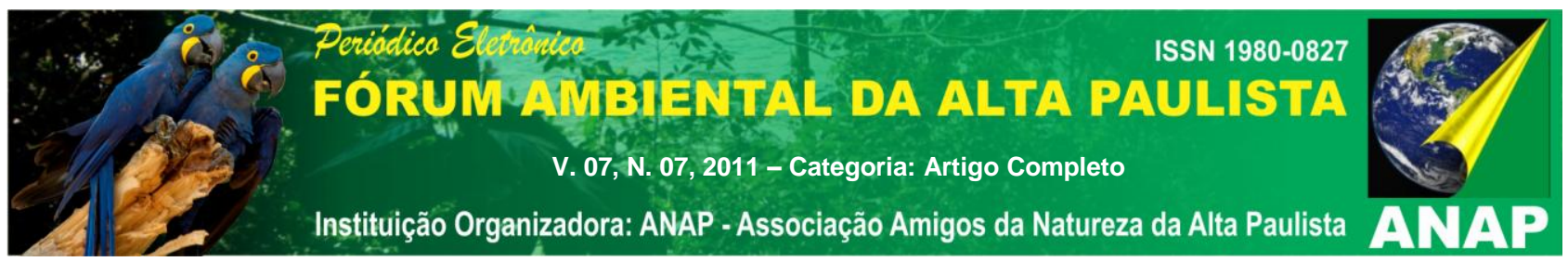

\title{
ANÁLISE ECODINÂMICA, COMPARATIVA, EM MICRO - ESCALA DA INFLUÊNCIA DE PLANTIOS ANTIGOS DE ALGAROBEIRAS (PROSOPIS JULIFLORA (SW) DC), MONTEIRO-PB
}

\author{
Maria Betânia Moreira Amador ${ }^{1}$ \\ Antonio Carlos de Barros Corrêa ${ }^{2}$
}

RESUMO: O trabalho que se apresenta tem o objetivo de averiguar, através de uma abordagem sistêmica, a influência de plantios antigos de algarobeiras (Prosopis juliflora (SW) DC) na biota local do município de Monteiro/PB. Como recurso metodológico optou-se pela aplicação da análise ecodinâmica em micro-escala, na qual se recorreu aos procedimentos de levantamento de campo utilizando-se o GPS Garmin Etrex para registro de coordenadas geográficas em UTM, recursos digitais disponibilizados em órgãos públicos tais como EMBRAPA, CPRM e outros. Para o registro de fotografias utilizou-se máquina fotográfica comum e, também em alguns momentos, a câmera digital RICOH 500SE, própria para trabalhos de campo pelo registro de coordenadas na fotografia. Outro instrumento importante utilizado foi Higrômetro, fundamental para a medição e registro da temperatura e da umidade relativa sob as copas das árvores. Todos os dados foram digitados em planilha Excel do programa Surfer permitindo assim, a elaboração dos cartogramas de isovalores ambientais. Os mesmos, após análise, foram confrontados com os mapas de uso da terra elaborados em Corel 12. Pode-se dizer que um dos resultados da pesquisa foi a percepção de que a algarobeira não traz somente impactos negativos para a biota local do município de Monteiro-PB, mas também influências positivas e, nesse caso apresentado, em especial, com relação a presença de animais endêmicos da localidade, bem como adequação favorável ao bem-estar animal em termos de temperatura e umidade em áreas de pasto.

Palavra-chave: Algarobas. Ecodinâmica. Geografia.

\footnotetext{
${ }^{1}$ Pós-doutoranda em Geografia, UFPE. Professora Adjunta da UPE - Campus Garanhuns. betaniaamador@yahoo.com.br

$\overline{2}$ Supervisor do Pós-doutorado em Geografia, UFPE. Professor Adjunto da UFPE. dbiase@terra.com.br
} 


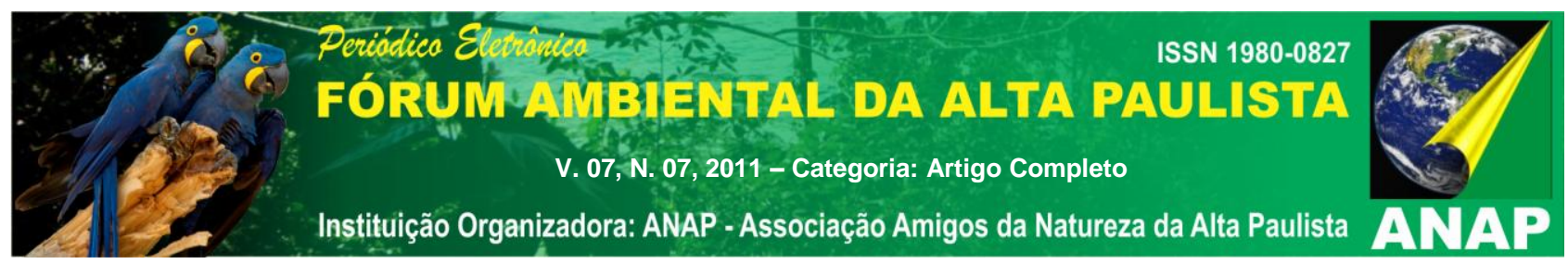

\section{INTRODUÇÃO}

Apresenta-se a seguir, sinteticamente, análise em micro-escala de duas propriedades no município de Monteiro - PB, cujas áreas possuem plantios antigos de algarobeiras, sendo uma delas de cunho particular e com atividade pecuária. E outra, com parte da área em terras públicas apresentando exploração, também predominantemente pecuária, ressaltando-se que em ambas as propriedades, a exploração é privada. (Figura 1).

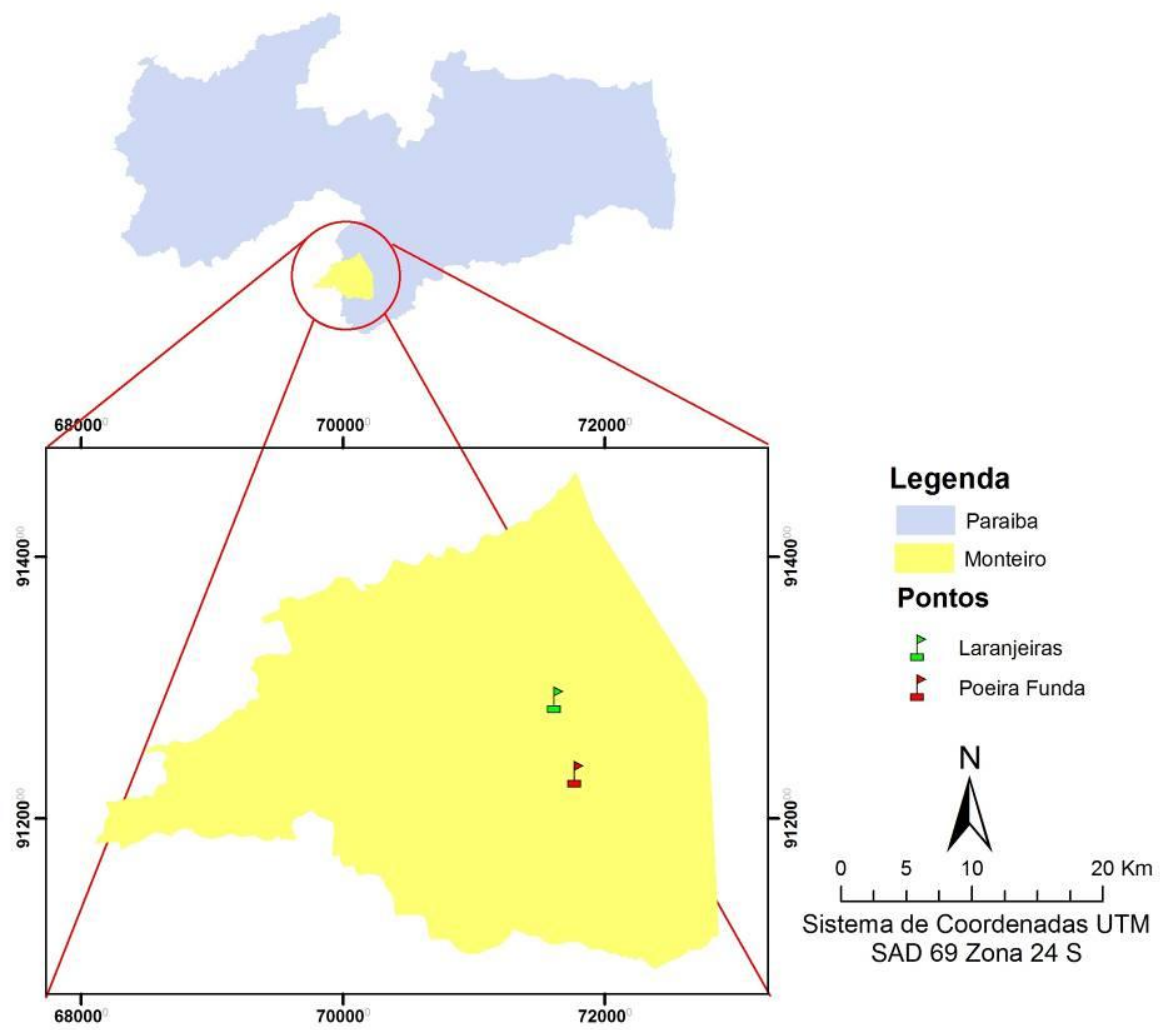

Figura 1: Localização das propriedades analisadas em Monteiro / PB Fonte: Pesquisa de campo, 2010. 


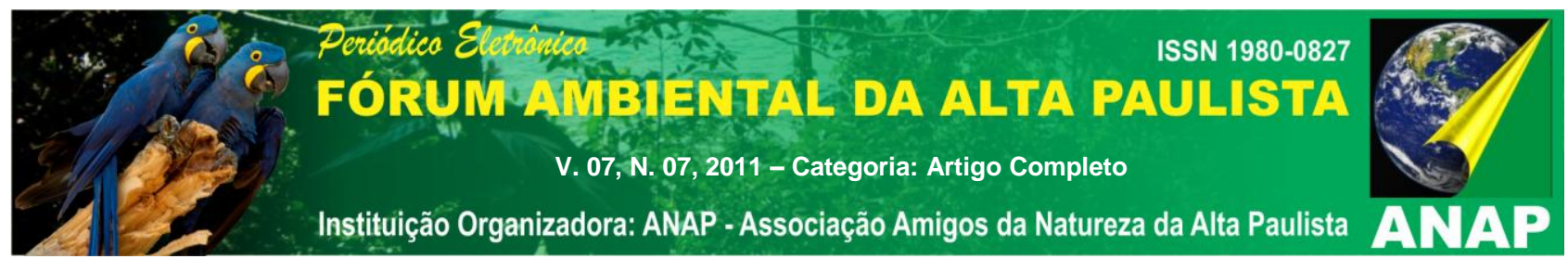

Desenho: Hewerton Silva

As propriedades em foco situam-se relativamente próximas ao Açude Novo, tendo a propriedade Poeira Funda a particularidade de ter suas terras em área de represa e por isso, embora pública é explorada, como outras na mesma condição com fins pecuários e, em alguns momentos, exploração de madeira proveniente das algarobeiras.

\section{Observações com base mofodinâmica e biogeográfica}

Assinala-se que por ocasião do primeiro trabalho de campo para reconhecimento e demarcação das coordenadas geográficas, percebeu-se que nessa área de represa havia um algarobal antigo (Figuras 2 e 3), representado pelo aspecto de árvores velhas e, segundo informação colhida no local, com mais de 40 anos de existência além de não se constituir em reflorestamento oficial e, sim espontâneo.

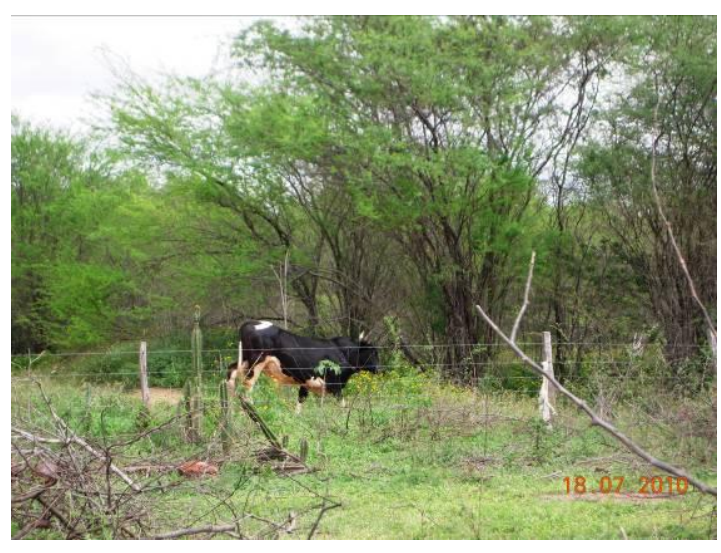

Figura 2: Bovino em área algarobada Fonte: Pesquisa de campo, jul. 2010 Foto: Maria Amador

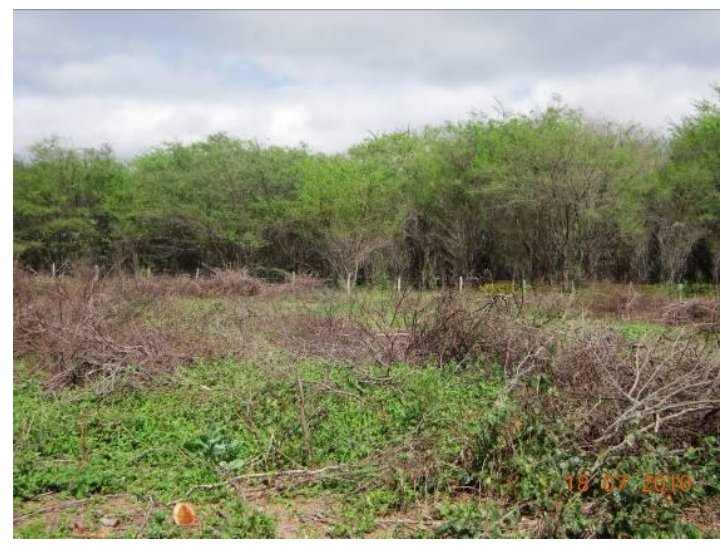

Figura 3: Aspecto antigo de algarobal Fonte: Pesquisa de campo, jul. 2010 Foto: Maria Amador

Também se observou assoreamento forte em algumas partes da área podendo-se visualizá-los através das fotos 4 e 5 . Na primeira foto, aparece a 


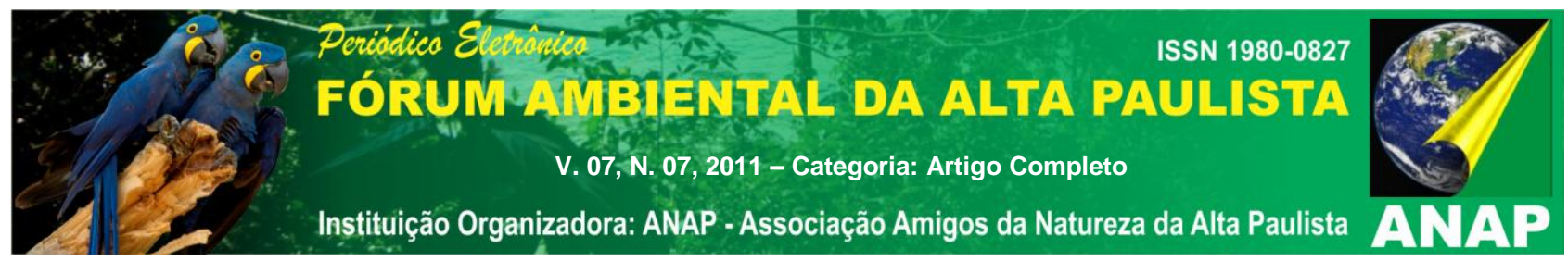

formação de degraus inferiores a $50 \mathrm{~cm}$ de altura, enquanto que na segunda foto salienta-se o aparecimento das raízes das árvores. Pode-se afirmar, então, que se trata de um processo de ravinamento forte visto que "até $50 \mathrm{~cm}$ de largura e profundidade são consideradas ravinas; acima de $50 \mathrm{~cm}$ de largura e profundidade, são denominadas voçorocas", de acordo com o Instituto de Pesquisas Tecnológicas IPT (1989) apud FLOREZANO (2008, p.21).

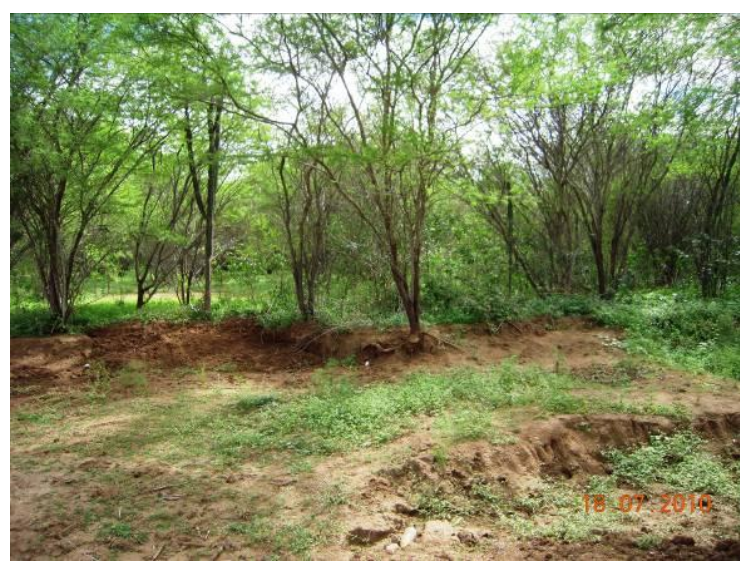

Figura 4: Aspecto do assoreamento Fonte: Pesquisa de campo, jul. 2010 Foto: Maria Amador

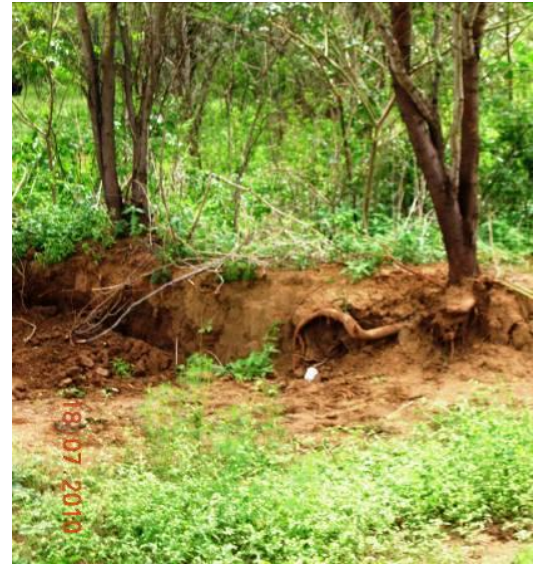

Figura 5: Aparecimento de raízes por assoreamento Fonte: Pesquisa de campo, 2010 Foto: Maria Amador

Outra importante observação realizada nessa área algarobada foi a presença de vários sagüins nas árvores. Ressalta-se esse fato por se detectar poucos trabalhos referentes a animais interagindo com essa espécie vegetal. Enfatizando-se esse ponto, registra-se que no levantamento bibliográfico realizado identificou-se a seguinte passagem: "ecologicamente, observa-se que está havendo uma adaptação da fauna regional a esta planta, pois algumas espécies de pássaros já nidificam em seus galhos e muitos animais nativos consomem suas vagens" (MENDES, 1989, p. 13).

Ou seja, tratando-se de um estudo que busca um olhar sistêmico, não se pode deixar de salientar que foi significativo registrar tal presença, conforme 


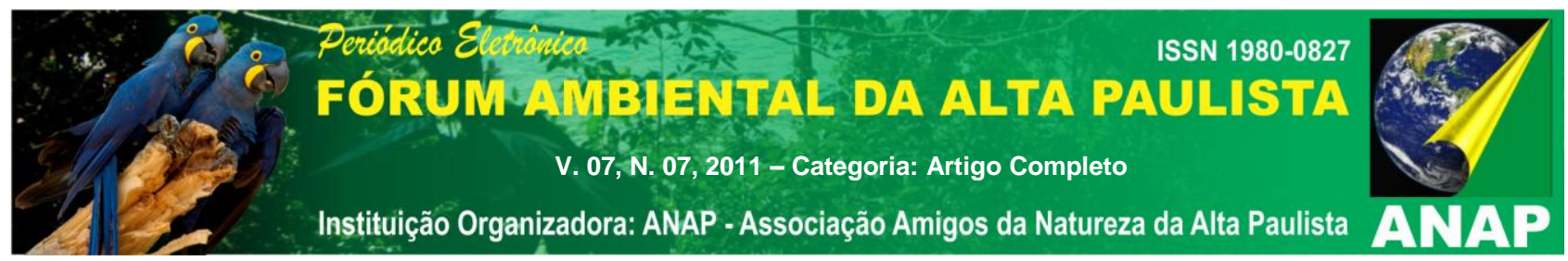

atesta a figura 6. É uma prova de que a espécie Prosopis juliflora (SW) DC fornece algum tipo de abrigo e alimento para certos grupos e/ou tipos de animais como é o caso citado e não somente causando impacto no sentido de afastar animais endêmicos, Também se verificou que o pássaro denominado localmente como "casaca de couro" aparentemente, tem preferência por formar seus ninhos nos galhos das algarobeiras (Figura 7), fato que se verificou em todas as áreas visitadas no município.

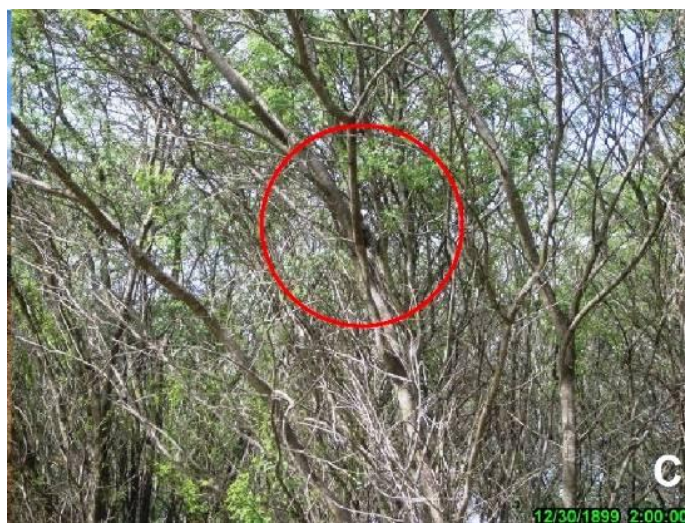

Figura 6: Saguim nas algarobeiras Fonte: Pesquisa de campo, jul. 2010 Foto: Tiago Henrique

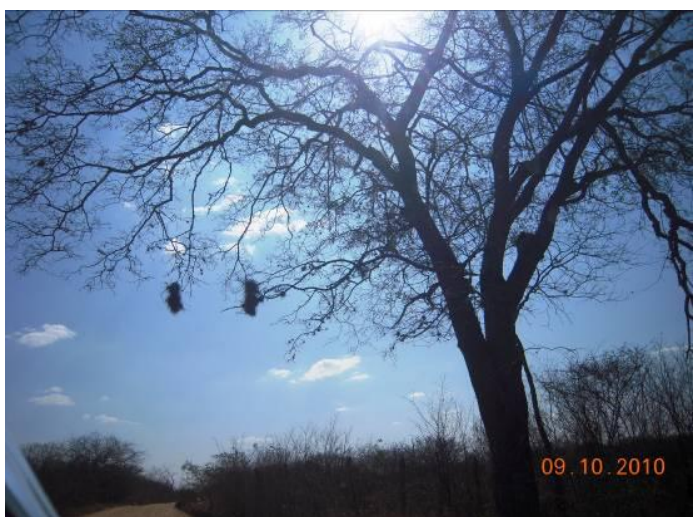

Figura 7: Ninhos de "casaca de couro" Fonte: Pesquisa de campo, jul. 2010 Foto: Maria Amador

Em termos de unidades de paisagem, que associam formas do modelado à sua cobertura pedológica, tem-se em Monteiro que as propriedades situam-se nos Topos e Altas Vertentes, cujos solos são Bruno não Cálcico, raso e com fertilidade natural alta (CPRM, 2005). No entanto, pela classificação atual, esses solos são denominados Luvissolos.

São solos que apresentam elevados teores de minerais primários decomponíveis, argila de atividade alta, são medianamente profundos e rasos no geral, evidenciam descontinuidade litológica entre os horizontes superficiais e subsuperficiais. Onde ocorrem, observa-se com freqüência presença de pedregosidade superficial (Calhaus ou Matacões) o que se denomina Pavimento 


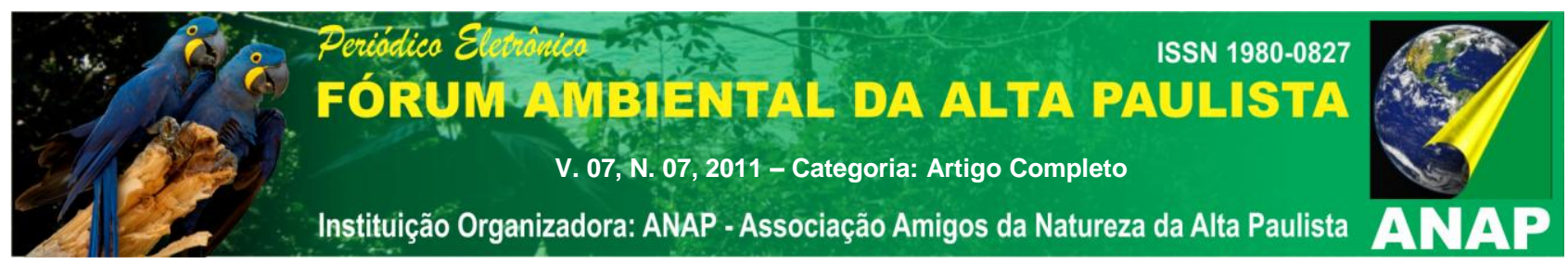

Desértico. São bastante susceptíveis à erosão. O caráter Vértico ocorre com bastante freqüência (quando presente, este caráter atribui ao solo valores mais elevados para a Atividade da Argila). Fatores Restritivos: condições climáticas desfavoráveis (MENDONÇA, 2006, p. 95)

É importante observar que este solo Bruno não Cálcico (atual Luvissolo), predomina em quase toda extensão do município, coincidindo, em grande parte, com o Complexo Sertânia. Mas, no caso específico aqui tratado tem-se uma das propriedades no Complexo Serra de Jabiatacá, a Laranjeiras, enquanto a outra, Poeira Funda está situada no Complexo Sumé (CPRM, 2005).

\section{Espacialização da temperatura nas parcelas analisadas nas propriedades Laranjeiras e Poeira Funda}

Para elucidar melhor a questão da temperatura nas áreas algarobadas e, principalmente, sob as algarobeiras, resolveu-se registrar a temperatura nas células analisadas por ocasião da tomada de dados para o estudo morfodinâmico da paisagem e espacializar essa informação à semelhança dos cartogramas de isovalores ambientais dos níveis categóricos no contexto de análise morfodinâmica da paisagem. Assim, apresenta-se o primeiro desses cartogramas na figura 8 , a seguir.

Para esse trabalho, utilizou-se um higrômetro e realizou-se medições à altura da copa, ou seja, à uma distância aproximada de 1,70 metros do solo obtendo-se duas marcações, uma para a temperatura mínima e outra para a temperatura máxima, utilizando-se no preenchimento da planilha Excel o valor médio das temperaturas, salientando-se que o mesmo procedimento foi adotado para a espacialização da umidade. 

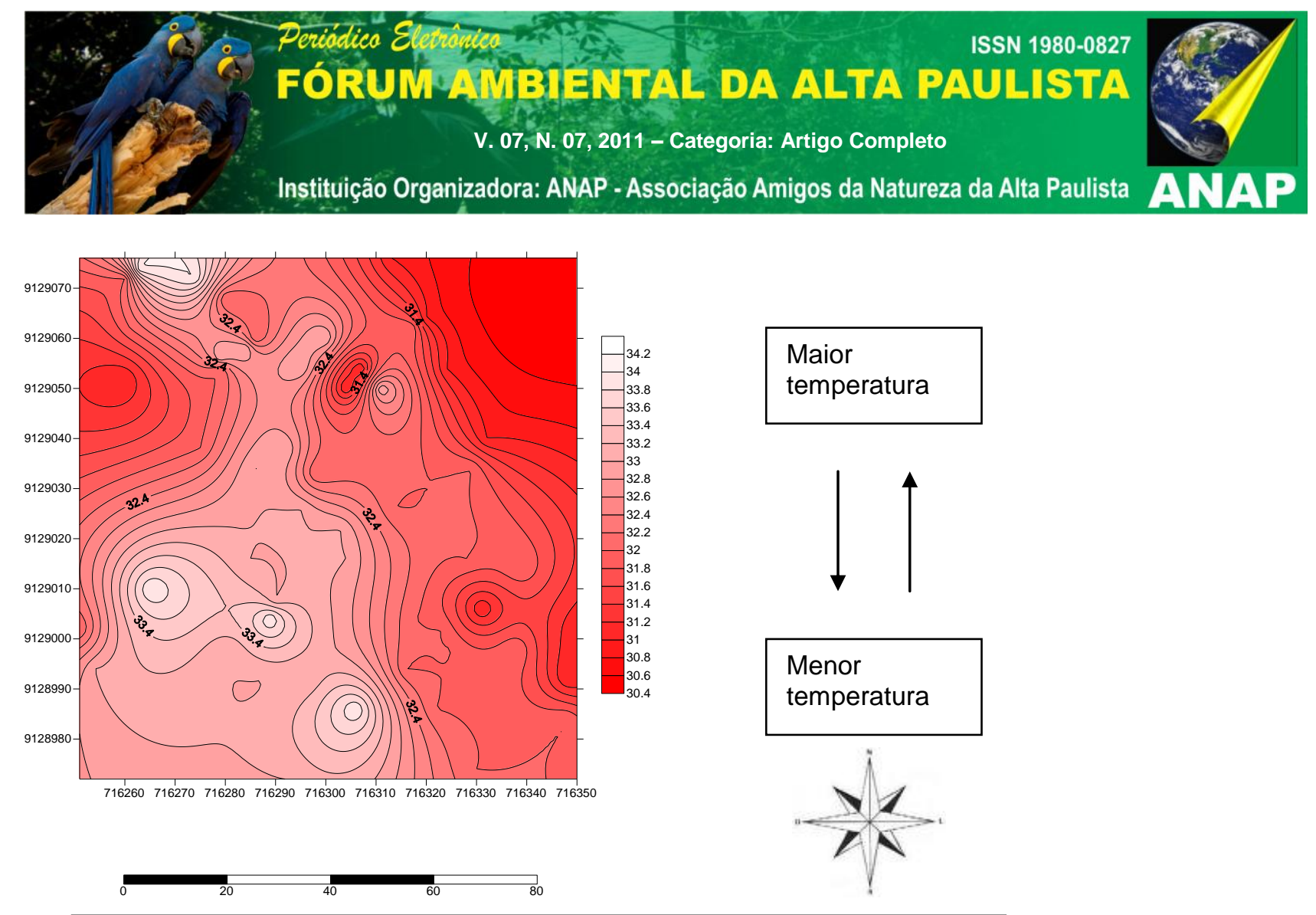

Figura 8: Cartograma representativo da espacialização da temperatura no hectare analisado (Laranjeiras).

Fonte: Pesquisa de campo, nov. 2010

Logo, o que se percebe pela figura 8 é que nas áreas onde há maior concentração de árvores tem-se menor temperatura, perceptível de visualização pelas nuances de vermelho escuro visível no cartograma, ou seja, a tonalidade vermelha escuro é indicador de temperatura mais baixa que, no caso considerado, ficou em torno de $30,4^{\circ} \mathrm{C}$, enquanto nas áreas correspondentes às tonalidades vermelho claro, quase brancas, ficou em torno de $34,0^{\circ} \mathrm{C}$, significando uma diferença de $4^{\circ} \mathrm{C}$.

É importante fazer-se essa referência devido a existência na bibliografia disponível sobre a associação sombra e bem-estar animal em áreas algarobadas (Figura 9 e 10), o que na região semiárida sempre foi considerado um fator fundamental tendo-se em vista as altas temperaturas que assola 0 nordeste brasileiro. Em estudos realizados na Argentina e publicados na década de 1980 , foi verificado que animais pastando em áreas que sofreram derrubadas de árvores de forma intensa chegaram a perder até $1 / 4 \mathrm{~kg}$ de seu peso por 


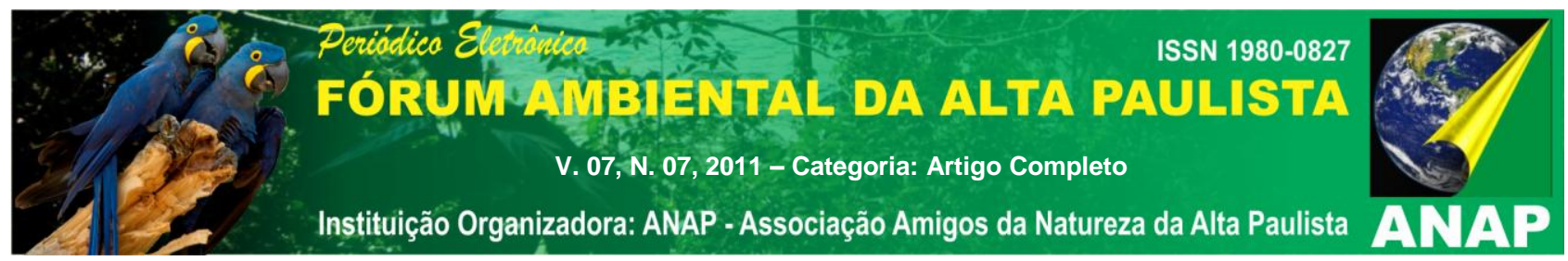

indivíduo/dia, representando ao final de 3 meses o quantitativo de $30 \mathrm{~kg}$ por animal (KARLIN; AYERZA, 1982, p.168).

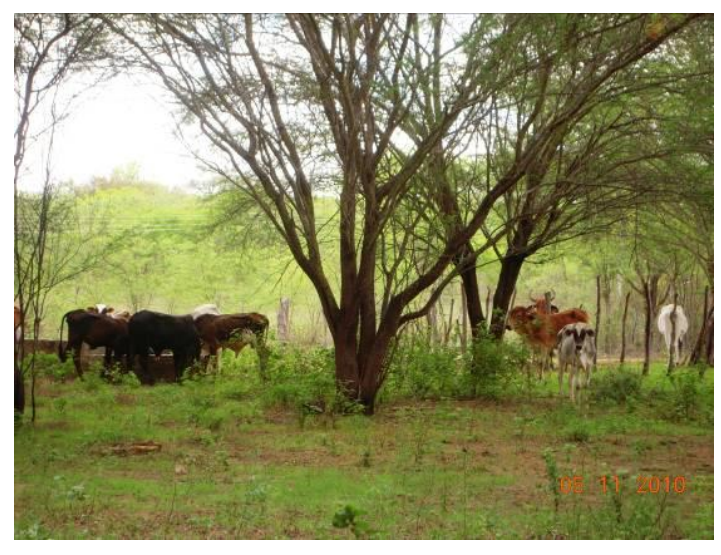

Figura 9: Gado reunido à sombra da algarobeira e em busca de água (Laranjeiras).

Fonte: Pesquisa de campo, Nov., 2010.

Foto: Maria Amador

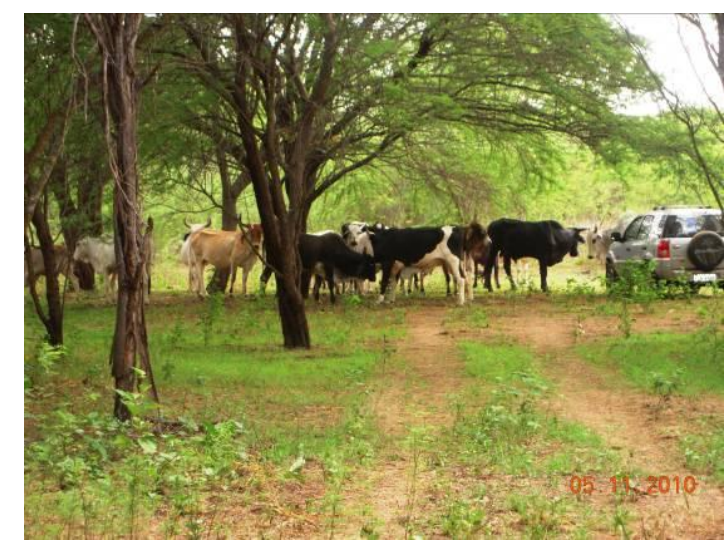

Figura 10: Outra visão do gado na sombra das algarobeiras (Laranjeiras). Fonte: Pesquisa de campo, Nov., 2010. Foto: Maria Amador

Registra-se, ainda, que na figura 9 há a reunião do gado em torno de tanque em busca de água, no entanto o mesmo estava seco. Ao ser indagado sobre o fato, o proprietário disse que uma vez por dia, geralmente ao entardecer, um vaqueiro abre a porteira para que o gado se dirija ao açude nas proximidades e, assim, sacie sua sede.

Nesse ponto cabe trazer à tona a informação de que o gado dessa propriedade é de corte e, pode-se observar in locu que os mesmos encontravam-se relativamente magros. Ora, se tem pasto mesmo que considerado "sujo" (grosseiro e pouco nutritivo), e the é dado ração industrializada também, segundo informação recebida, o resultado deveria ser melhor. Considera-se, então, importante lembrar que "tudo que causa stress ao gado diminui a produção" (PRIMAVESI, 2004, p. 54).

Em seqüência, apresenta-se o cartograma de espacialização da temperatura da propriedade Poeira Funda (Figura 11) que, por sua vez, mostra 


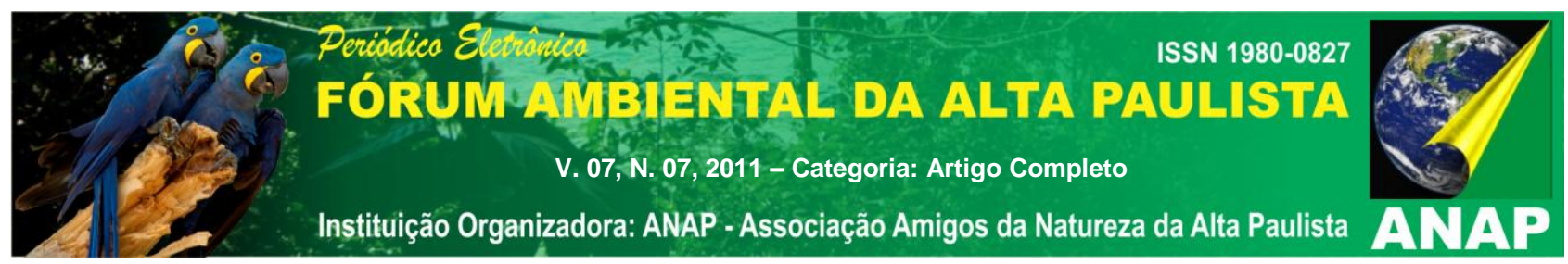

áreas de maior temperatura acompanhando as células que foram sujeitas ao fogo.
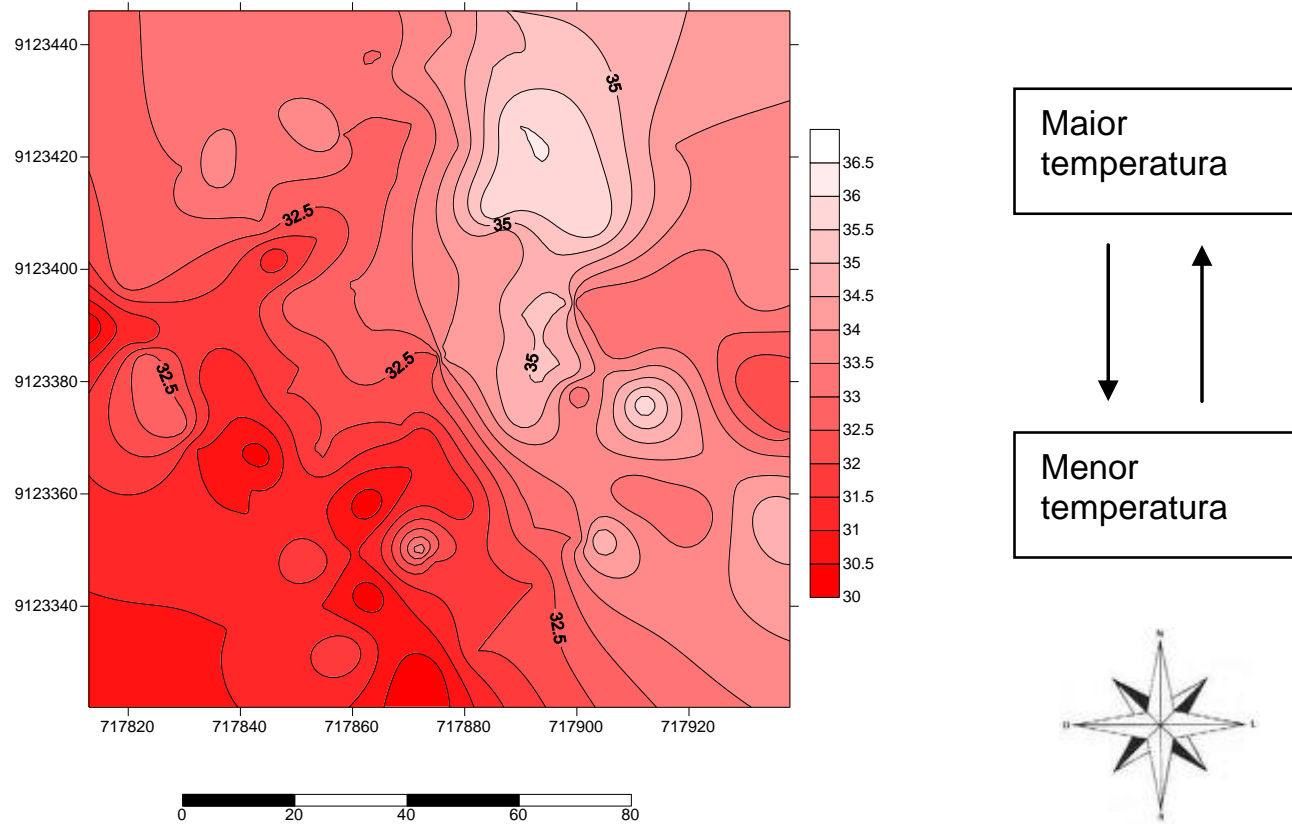

Figura 11: Cartograma representativo da espacialização da temperatura no hectare analisado (Poeira Funda).

Fonte: Pesquisa de campo, nov. 2010

Registra-se, no entanto, que a sensação térmica sentida pelo efeito da temperatura, ainda alta no momento de coleta de dados à altura do solo parecia ser bem forte. Porém, na altura da cabeça, o que equivale a mais ou menos de 1,65 m do chão, sentia-se temperaturas mais amenas, percepção que se pode associar ao descampado que se formou pela derrubada das árvores facilitando a circulação do vento.

Já as áreas indicativas de menores temperaturas, as quais podem ser identificadas na porção sudoeste do cartograma pela tonalidade vermelho mais escuro, corresponde ao espaço de algarobal mais frondoso, perto da cerca e da porteira, local onde os animais se reúnem para entrar ou sair dessa parcela. 


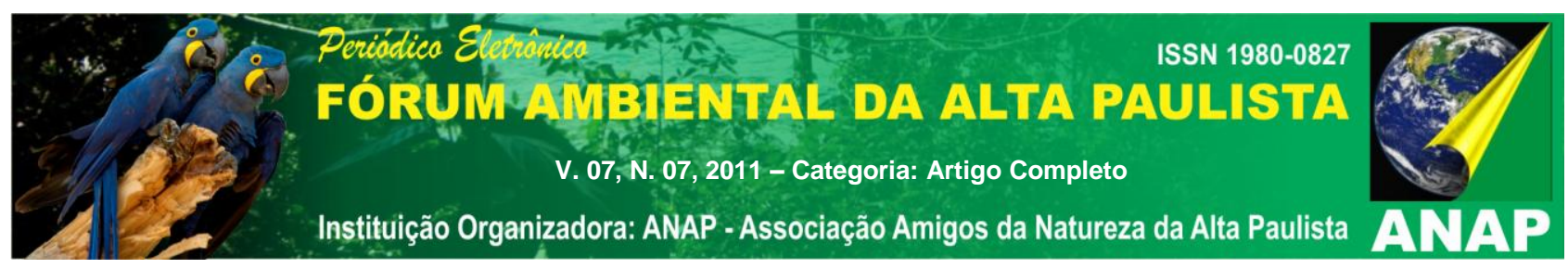

\section{Espacialização da umidade nas parcelas analisadas das propriedades Laranjeiras e Poeira Funda}

Com relação a questão da umidade, observa-se que os pontos indicativos de menor umidade correspondem às áreas abertas, seja por trânsito constante de animais, seja por derrubada de algarobeiras. No cartograma em foco (Figura 12), pode-se visualizar essas áreas no canto inferior direito, no centro e próximo ao canto superior esquerdo demarcado pela tonalidade de cinza mais forte locais onde a medição de umidade indicou valores entre $41 \%$ e $48 \%$.

Em termos de conforto animal torna-se difícil para quem não é especialista no assunto fazer considerações precisas, no entanto pode-se ter a literatura como referência e nesse sentido toma-se mais uma vez Primavesi (2004), quando ela discute sobre o clima e o aproveitamento da forragem e traz dados elaborados por Bianca (1973) em Nascimento (1975) a respeito de temperaturas críticas e conforto térmico de gado, ou seja:

A "zona de conforto" para o gado é relativamente pequena. Para as raças européias está entre $-1^{\circ} \mathrm{C}$ e $16^{\circ} \mathrm{C}$, com uma umidade relativa do ar entre 50 a $80 \%$, e para o gado indiano, nosso zebu, é de 10 a $27^{\circ} \mathrm{C}$, com uma umidade relativa do ar próxima da saturação. Os mecanismos termorreguladores começam a falhar no gado europeu a partir de $27^{\circ} \mathrm{C}$ e no gado zebuíno a partir de $35^{\circ} \mathrm{C}$. Por isso o gado faz um mínimo de movimentos para não produzir mais calor, reduzindo as caminhadas, a ingestão de alimento e a metabolização. Conseqüentemente ocorre um declínio na produção e do peso, por aproveitar bem a forragem (BIANCA, 1973 em NASCIMENTO apud PRIMAVESI (2004, p.30). 

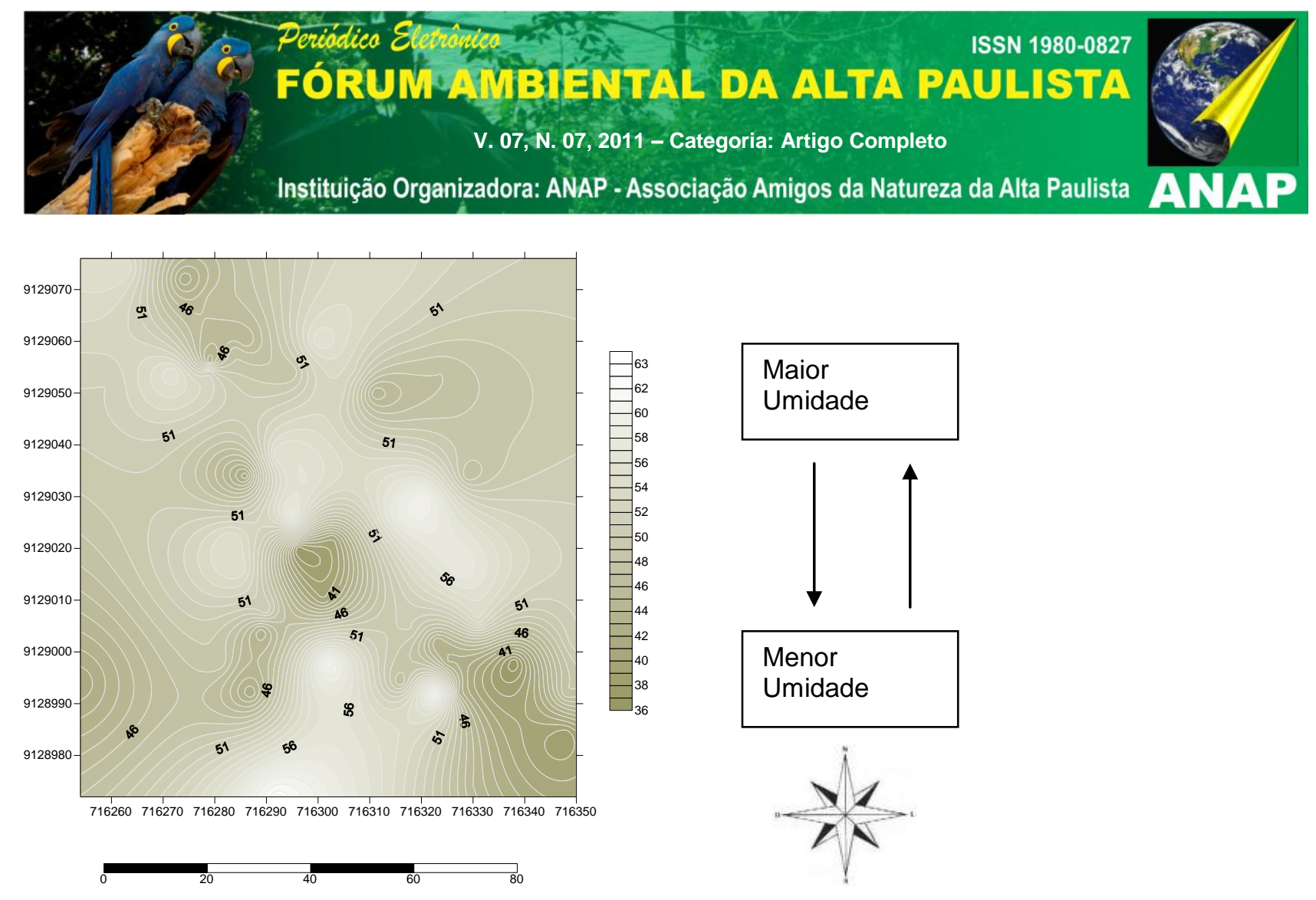

Figura 12: Cartograma representativo da espacialização da umidade no hectare analisado (Laranjeiras).

Fonte: Pesquisa de campo, nov. 2010.

Percebe-se, então, que no caso específico do gado e da propriedade considerada tem-se, muito provavelmente, uma adequação em termos de temperatura e umidade relativa do ar visto que o proprietário afirmou tratar-se de gado mestiço a partir de cruzamento da raça Nelore com gado da terra, ou seja, espera-se que o gado da terra tenha características fortes em relação a temperatura compensando as características de sensibilidade da origem Nelore, enquanto que em relação à umidade está dentro do aceitável visto que mesmo no Nelore a umidade do ar para o conforto animal fica, teoricamente, no intervalo de 50 a $80 \%$ e na coleta de dados registrou-se um intervalo entre 36 a $63 \%$, logo coerente com a literatura especializada no assunto.

Em continuação, apresenta-se outra propriedade em que se fez análise semelhante. A característica básica e diferenciadora da primeira (Laranjeiras), é 


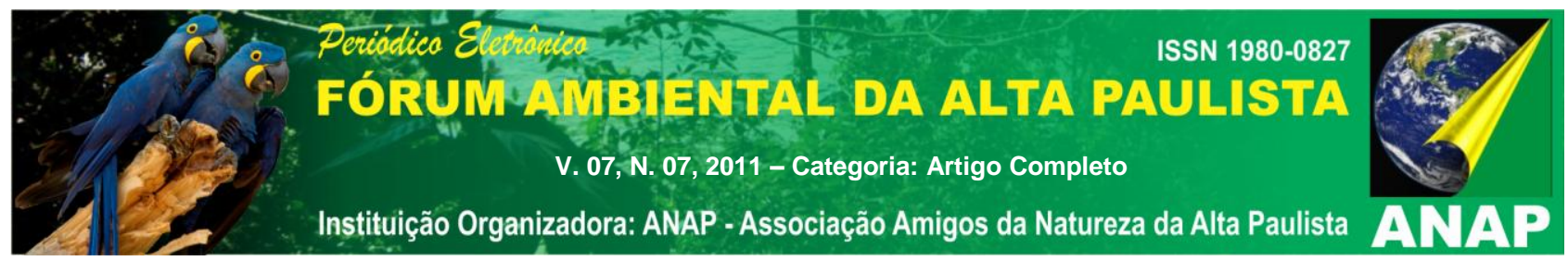

que suas terras têm caráter público e de uso privado. Ou seja, a área situa-se no conjunto de uso da terra de uma represa.

Assim, em termos de umidade, a propriedade Poeira Funda (Figura 13), evidencia menores índices de umidade na parte superior do cartograma, o que corresponde aos locais identificados com temperaturas mais elevadas. Por outro lado, as áreas que mostram valores de maior umidade são aquelas onde há elevada concentração de algarobeiras com amplas copas e muitas delas bifurcadas.

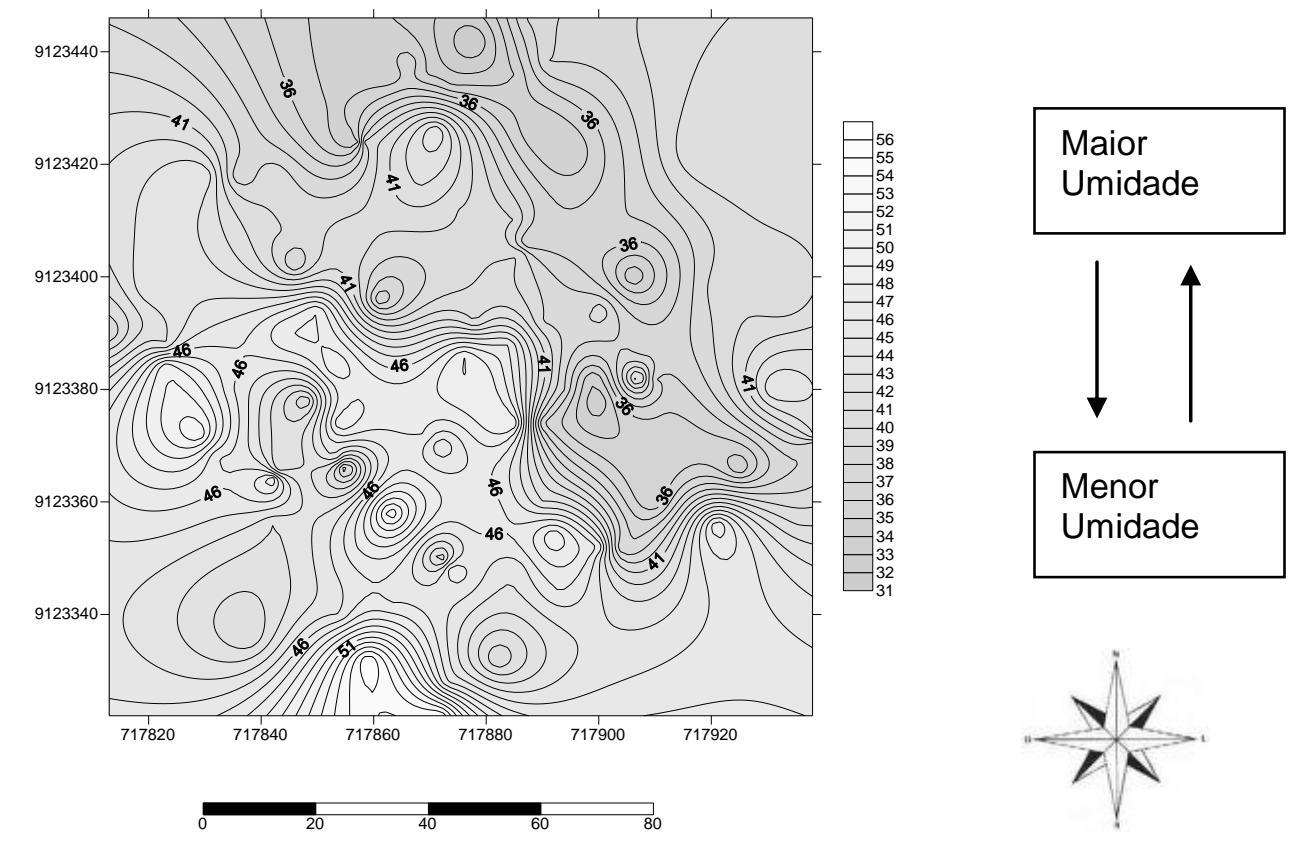

Figura 13: Cartograma representativo da espacialização da umidade no hectare analisado (Poeira Funda).

Fonte: Pesquisa de campo, nov. 2010.

Resultado da análise morfodinâmica das propriedades Laranjeiras e Poeira Funda - Monteiro/PB 


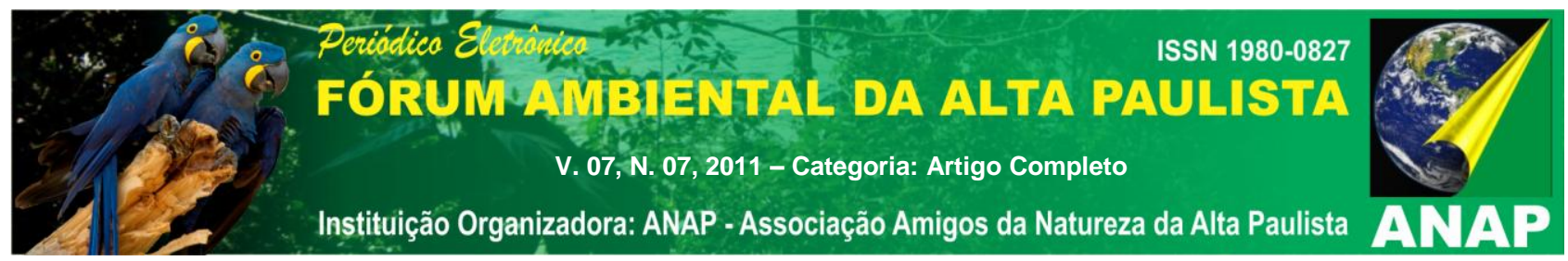

Ressalta-se a importância de confrontar as partes já dispostas e comentadas em separado, através de cada cartograma de isovalores de estabilidade ambiental com o Mapa de Uso da Terra com indicações morfodinâmicas e biogeográficas (Figuras 14 e 15), os quais foram elaborados em Corel 12, com base em croqui de campo, no contexto da análise ecodinâmica da paisagem.
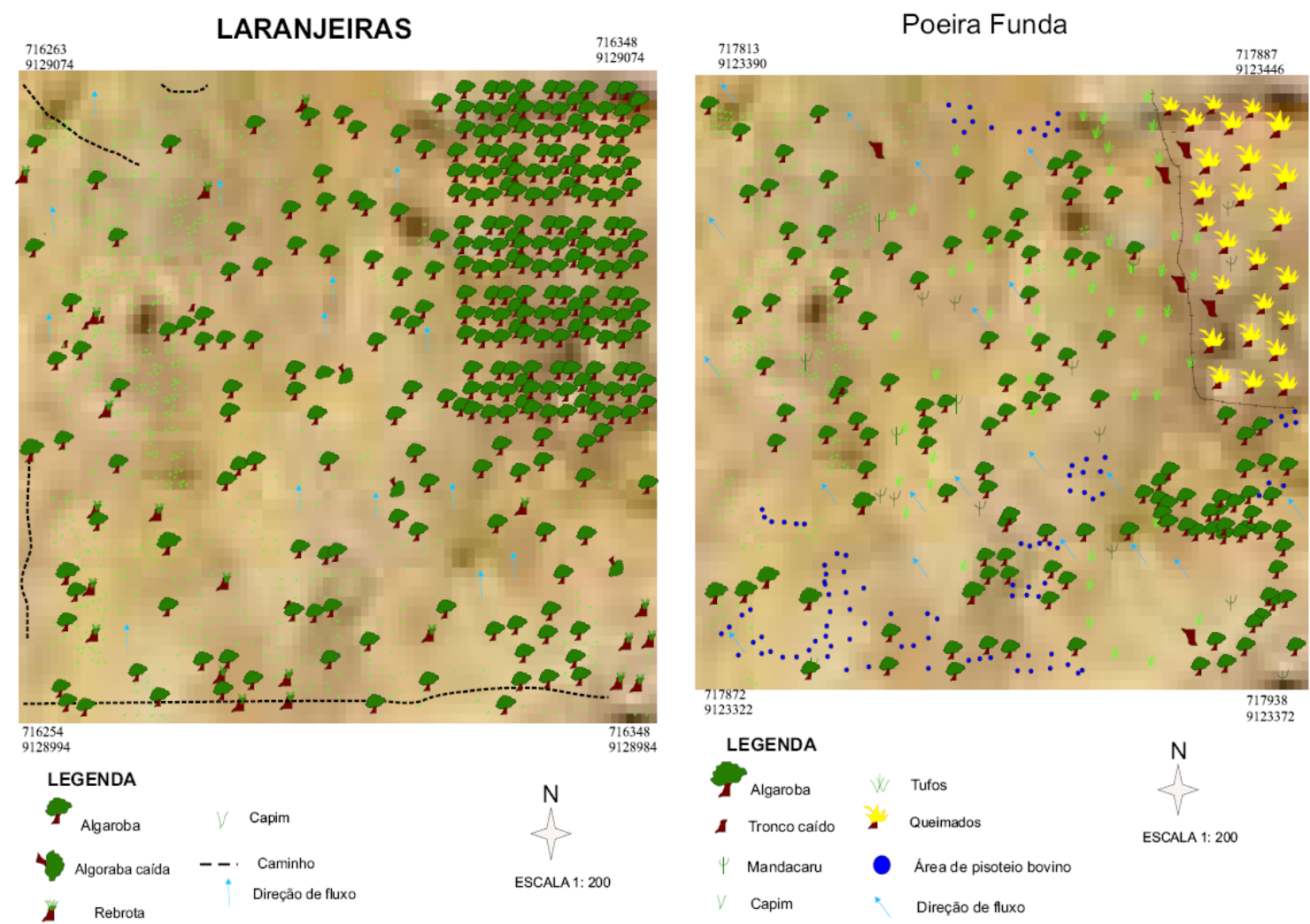

Figura 14: Mapa de uso da terra com indicações morfodinâmicas (Laranjeiras Monteiro / PB).

Fonte: Pesquisa de campo, nov., 2010

Figura 15: Mapa de uso da terra com indicações morfodinâmicas (Poeira Funda - Monteiro / PB).

Fonte: Pesquisa de campo, nov., 2010 (Desenho: Cristiane Barbosa).

O conceito de "morfodinâmica" introduzido por Jean Tricart (1977) constitui o conjunto de processos interconectados responsáveis pela gênese do modelado. Para Corrêa (2006) estes processos comandam a divisão da 


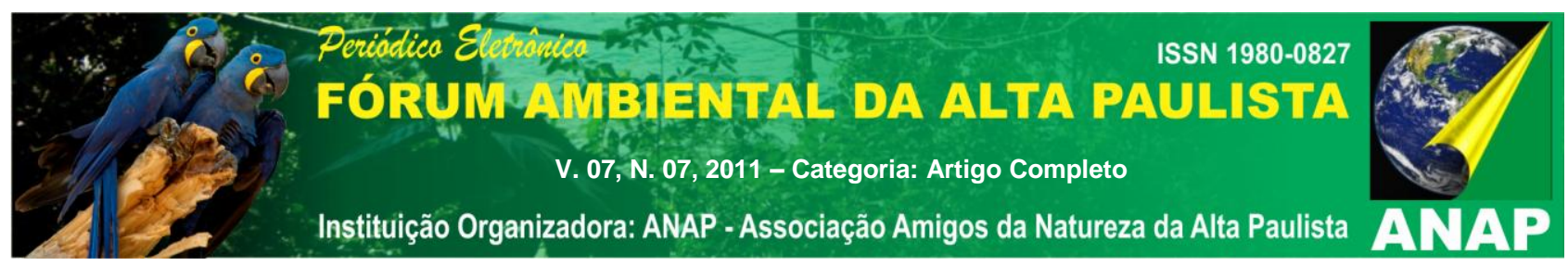

paisagem em unidades homogêneas obedecendo a uma perspectiva sistêmica (VASCONCELOS et al., 2007, p. 38).

A propriedade Laranjeiras (Figura 14) evidencia, através de seu mapa de uso da terra, a distribuição das árvores de forma razoavelmente esparsa, o que permite melhor movimentação do gado, mas também coincide com uma temperatura relativamente mais elevada. Porém, nos locais de maior concentração de algarobeiras verifica-se um significativo decréscimo de temperatura, o que para o gado é significa conforto térmico.

Quanto à umidade, constatou-se certo equilíbrio de percentual em todo o hectare analisado, ressaltando-se que o ponto crucial, ou seja crítico coincide no quadrante inferior direito, justamente onde detectou-se árvores derrubadas e solo exposto. Ou seja, o item umidade está de acordo com as necessidades dos animais postos para pastar.

Em sequência, o mapa de uso da terra com indicações morfodinâmicas (Figura 15), da propriedade Poeira Funda sintetiza o padrão de uso encontrado no hectare analisado, de forma a ajudar na compreensão, através da visualização dos elementos referenciados na análise em micro-escala, dos níveis categóricos, até então, evidenciados em cartogramas de isovalores de estabilidade ambiental.

Logo, é possível perceber, de forma aproximada, a distribuição das algarobeiras, a localização da cerca e da área desmatada e queimada, bem como tocos e/ou rebrotas de algaroba por entre o algarobal, também é possível perceber as principais áreas de pisoteio animal $\mathrm{e}$, os locais de maior concentração de capim embaixo das árvores, presença de mandacarus e a direção dos fluxos d'água por ocasião das chuvas.

Diferentemente da propriedade Laranjeiras, essa segunda propriedade, a Poeira Funda, talvez por não seguir as exigências de demanda de um proprietário atrás de lucro a qualquer preço, tenha apresentado parâmetros 


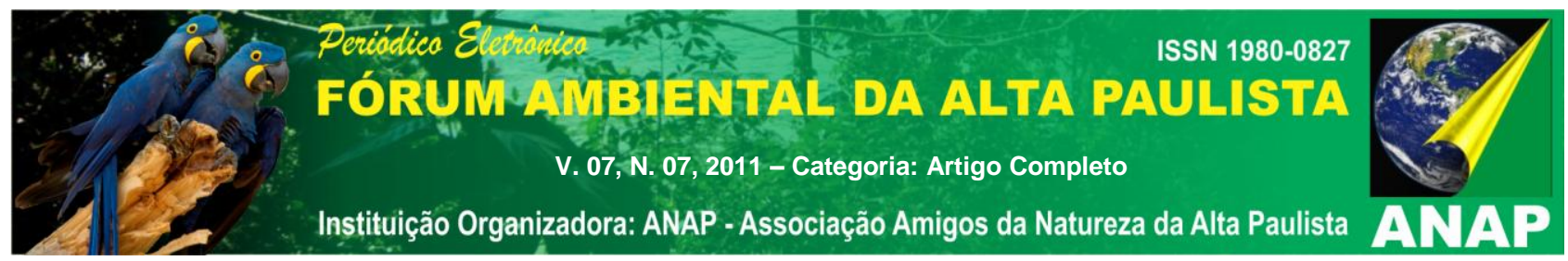

estruturais e funcionais biogeográficos que indicam um melhor direcionamento para o que se denomina de sustentabilidade.

Ou seja, as condições ambientais se mostraram mais equilibradas tanto em termos de fauna quanto de flora, ou melhor, de distribuição na terra de algarobas e capins. O problema reside mesmo nas condições de ordem geomorfológicas pelos indícios de fortes assoreamentos e frágil estrutura do solo para suportar o pisoteio freqüente do gado.

\section{REFERÊNCIAS}

AMADOR, Maria Betânia Moreira. Abordagem geográfica de antigas áreas algarobadas através do estudo sistêmico dos processos superficiais da paisagem e sua influência na biota local: Monteiro/PB. 2011. 125f. (Relatório de Pós-Doutorado em Geografia) - Centro de Filosofia e Ciências Humanas. Universidade Federal de Pernambuco, Recife.

A visão sistêmica e sua contribuição ao espaço pecuário de Venturosa e Pedra no Agreste de Pernambuco, 2008. 316f. Tese (Doutorado em Geografia) - Centro de Filosofia e Ciências Humanas. Universidade Federal de Pernambuco, Recife.

AMADOR, Maria Betânia Moreira. A política de reflorestamento e seus reflexos na estruturação do espaço agrário semi-árido nordestino: 0 caso do reflorestamento com algarobeiras no município de Custódia-PE, 1994. 214f. Dissertação (Mestrado em Geografia) - Centro de Filosofia e Ciências Humanas. Universidade Federal de Pernambuco, Recife.

ASSOCIAÇÃO BRASILEIRA DE NORMAS TÉCNICAS, NBR 6023: informação e documentação: referências: elaboração. Rio de Janeiro, 2002.

CORRÊA, Antonio Carlos de; AZAMBUJA, Renata Nunes. Avaliação qualitativa em micro-escala da estabilidade da paisagem em áreas sujeitas a desertificação no ambiente semi-árido do Nordeste do Brasil. Anais do XI Simpósio Brasileiro de Geografia Física Aplicada. USP: São Paulo, 2005.

CPRM. Serviço Geológico do Brasil. Projeto cadastro de fontes de abastecimento por água subterrânea. Diagnóstico do município de 


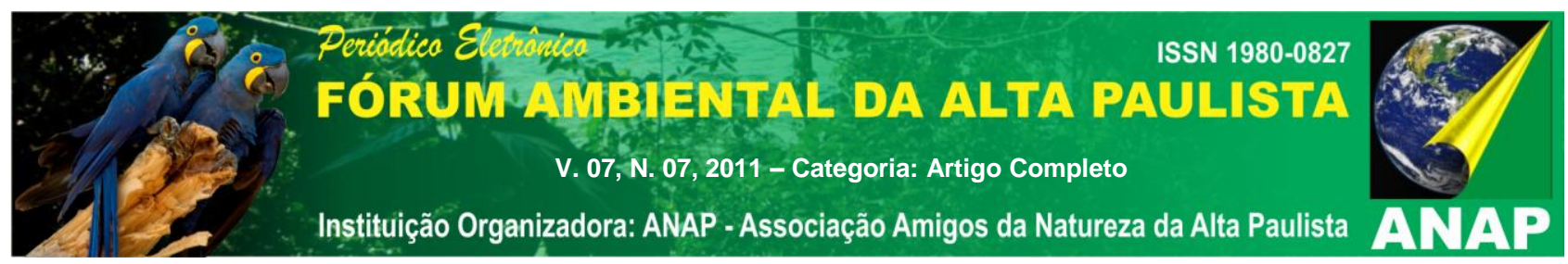

Monteiro, estado da Paraíba. Organizado por MASCARENHAS, João de Castro et al. Recife: CPRM/PRODEEM, 2005.

MENDES, Benedito Vasconcelos. Potencialidades de utilização da algaroba [Prosopis juliflora (SW) DC] no semi-árido brasileiro. 2 ed. Mossoró,RN: ESAM, 1989.

MENDONÇA, José Francisco Bezerra. Solo: substrato da vida. Brasília: Embrapa Recursos Genéticos e Biotecnologia, 2006.

PRIMAVESI, Ana. Manejo ecológico de paisagens: em regiões tropicais e subtropicais. São Paulo: Nobel, 2004.

TRICART, Jean. Ecodinâmica. Rio de Janeiro: IBGE: Diretoria Técnica: SUPREN, 1977.

VASCONCELOS, Talitha Lucena de et al. Estudo morfodinâmico em área do semi-árido do nordeste brasileiro: um mapeamento geomorfológico em microescala. Revista de Geografia: UFPE - DCG/NAPA, v. 24, n.2, mai / ago 2007. 